\title{
Comparación de la Fermentación de Bebida de Soya y Leche de Vaca utilizando un Cultivo Láctico Comercial
}

\author{
Martha María Cuenca* \\ Martha Cecilia Quicazán**
}

* Ingeniera Química, aspirante a Maestría en Ingeniería Química, Facultad de Ingeniería, Universidad Macional de Colombia, sede Bogotá, Colombia

e-mail:mmcuencaq@unal.edu.co

* * Msc. Ciencia y Tecnología de Alimentos, Ingeniera Química Profesora Asociada, Instituto de Ciencia y Tecnología de Alimentos-ICTA, Universidad Macional de Colombia, sede Bogotá, Colombia

e-mail: mcquicazand@unal.edu.co

Fecha de recepción: Moviembre 20 de 2003

Fecha de aprobación: Abril 30 de 2004

\section{RESUMEN}

Se evaluó la fermentación láctica de bebida de soya y de leche de vaca con un cultivo termófilo comercial (serie MY 800, marca Ezal ${ }^{\circledR}$ de Rhodia) para yogurt, conformado por Streptococcus thermophilus, Lactobacillus delbrueckii subsp. lactis y Lactobacillus delbruechii subsp. bulgaricus. Se efectuó seguimiento durante 7 horas de las variables de respuesta: acidez total, contenido de ácido láctico determinado por HPLC, pH y viscosidad. Tanto la bebida de soya como la leche de vaca acidificaron con un comportamiento similar y típico de la fermentación láctica. Los valores encontrados 
para la acidez total, el contenido de ácido láctico y la viscosidad fueron significativamente inferiores para la bebida de soya durante todo el periodo evaluado; sin embargo para los valores de pH, las diferencias se manifestaron solamente a partir de la quinta hora de fermentación. El contenido de ácido láctico en todos los casos fue menor al valor de acidez total y para el pH correspondiente a la coagulación, la proporción entre las dos variables de respuesta fue similar en las dos bebidas. Se detectaron otros ácidos orgánicos responsables de la acidez total, tales como el cítrico, málico, fumárico y butírico.

Palabras Clave: Leche, soya, fermentación láctica, ácido láctico, yogurt.

\section{ABSTRACT}

Soymilk and cow's milk lactic fermentation was evaluated by using a comercial lactic culture (MY 800 serie, Rhodia Ezal $\left.{ }^{\circledR}\right)$ constituted by Streptococcus thermophilus, Lactobacillus delbrueckii subsp. Lactis and Lactobacillus delbruechii subsp. Bulgaricus. There was a 7 hours follow-up of every response variables: total acidity, lactic acid content (determined by HPLC), $\mathrm{pH}$ and viscosity. Both soymilk and milk acidified with the similar and typical behavior of a lactic fermentation. Total acidity, lactic acid content, and viscosity of soymilk were significantly lower during all of the evaluated period. However, for $\mathrm{pH}$ values, differences were clearly expressed from 5 th hour on. Lactic acid content in all cases was lower than total acidity and for the $\mathrm{pH}$ corresponding to coagulation, the relation between the two variables was similar for both products. Other organic acids accountable for total acidity, as citric, malic, fumaric and butyric acid.

Key Words: soybean, soymilk, lactic fermentation, lactic acid, yogurt.

\section{INTRODUCCIÓN}

Tradicionalmente se denomina yogurt al producto obtenido a partir de leche de vaca higienizada, fermentada por acción de Lactobacillus delbrueckii ss. bulgaricus y Streptococcus salivarius ss thermophilus, los cuales deben ser viables, abundantes y activos en el producto hasta el final de su vida útil. El consumo del yogurt, originario de la región de los Balcanes y de los países de Oriente Medio, se ha extendido a los países occidentales y sus técnicas de fabricación se han modernizado en cuanto a los equipos utilizados y la pureza de los cultivos empleados, aunque los pasos básicos siguen siendo los mismos (Robinson y col., 1991).

Las bacterias ácido lácticas obtienen su energía a partir de carbohidratos; en el caso de la fermentación de leche de vaca el catabolismo de la lactosa ocurre en el interior de las células. Se ha reportado que el 5 . thermophilus produce principalmente ácido $L(+)$ láctico y preferiblemente sucede a temperaturas inferiores a $40^{\circ} \mathrm{C}$, mientras que el $L$. bulgaricus produce el ácido $\mathrm{D}(-)$ láctico y preferiblemente ocurre a temperaturas superiores a $45^{\circ} \mathrm{C}$. Mormalmente se encuentran los dos tipos de ácidos en el yogurt y la proporción entre los isómeros es indicativa de las condiciones bajo las cuales ha ocurrido el proceso. La velocidad de acidificación influye en la estructura y consistencia del coágulo y en la separación del suero. (Kroger y col, 1989; Robinson y col, 1991).

La importancia del ácido láctico en la producción del yogurt de leche de vaca radica en que, en primer lugar, contribuye a la desestabilización de las micelas de caseína mediante el paso del fosfato y del calcio de un estado coloidal a una forma soluble (lactato y fosfato cálcico) que difunde en la fracción acuosa de la leche, lo cual origina la precipitación de la caseína a valores de $\mathrm{pH}$ de 4,6 a 4,7, dando lugar al gel o coágulo que constituye el yogurt. En segundo lugar, proporciona el sabor de esta bebida, contribuye a acentuar el aroma y ayuda a la estabilidad microbiológica del producto debido a su comprobada acción controlante sobre flora indeseable (Oberman, 1985; Kroger, 1989).

Actualmente la soya se perfila como una materia 
prima importante para la elaboración de alimentos funcionales, denominados así aquellos cuyo consumo, además de proporcionar nutrientes, generan beneficios a la salud (Vasconcellos, 2001; USB, 2002). Se han llevado a cabo importantes esfuerzos para fabricar productos más aceptables y apetecibles a partir de esta leguminosa, fuente de proteína relativamente abundante y de bajo costo (Besler, 1999). También se han desarrollado procesos que disminuyan el sabor afrijolado y la flatulencia, mediante la fermentación láctica para la elaboración de productos similares al yogurt bien sea a partir de la bebida sola o de mezclas con leche de vaca o de otros mamíferos. El bajo pH del producto permite prolongar el tiempo de vida útil. (Buono y col., 1990, Cheng y col., 1990; Robinson, 1991).

Los carbohidratos fermentables de la soya son oligosacáridos de bajo peso molecular tales como sacarosa y los -galacto-oligosacáridos rafinosa, estaquiosa y verbascosa. Debido a la ausencia de -galactosidasa en el tracto intestinal humano, el destino metabólico de estos compuestos es incierto y a ellos se les atribuye la flatulencia de la soya. Por otro lado, algunos microorganismos ácido-lácticos poseen la enzima -galactosidasa, lo cual explica la factibilidad del proceso fermentativo de la bebida de soya por parte de estas bacterias (Pinthong, 1980c, Cheng y col., 1990).

Se ha evaluado el crecimiento de bacterias lácticas y su efecto en la producción de ácido, los compuestos volátiles que influyen en las características organolépticas y los niveles de oligosacáridos (Ankenman y col, 1996, Pinthong y col, 1980a, 1980b, 1980c). Se han utilizado $L$. bulgaricus y 5 . thermophilus solos y combinados. En la fermentación de bebida de soya se presentan dos etapas bien definidas y similares a las curvas de crecimiento características de los microorganismos. La adaptación registra una duración de dos horas y la etapa exponencial dura cinco horas o más. Seguidamente se presenta una postacidificación similar a la del yogurt de leche de vaca, cuya proporción depende de la temperatura de almacenamiento del producto (Lee y col., 1990).

El contenido de sólidos presentes en la bebida de soya tiene efecto sobre las características de la bebida fermentada. Las bebidas más diluidas $\left({ }^{\circ}\right.$ Brix $\left.<6,5\right)$ alcanzan valores de acidez menores, baja viscosidad y la alta sinéresis del producto (Chang, 1990; Quicazán y col., 2001).

En el presente trabajo se llevó a cabo la fermentación de bebida de soya y de leche de vaca bajo las mismas condiciones, utilizando un cultivo láctico termófilo liofilizado de uso comercial. Se efectuaron comparaciones de las curvas de acidificación evaluando la acidez total, el contenido de ácido láctico, el pH y la viscosidad. Se evaluó la proporción que representa el ácido láctico en la acidez total con el fin de ampliar el conocimiento de este proceso fermentativo.

\section{MATERIALES Y MÉTODOS}

\section{Materias primas}

Bebida de soya: fue elaborada según la metodología validada en trabajos anteriores (Quicazán y col., 2001). Se utilizó fríjol soya (Glycine max), variedad colombiana Soyica P33, proveniente de cultivos del departamento del Valle del Cauca, Colombia. Se efectuó una operación de estandarización de los sólidos totales en un valor igual a $7 \% \mathrm{P} / \mathrm{P}$.

Leche de vaca: proveniente de la Sabana de Bogotá, pasteurizada, homogenizada y estandarizada. El contenido de sólidos totales se estandarizó en 12\% P/P y la grasa en 3\% P/P.

Cultivo láctico: se empleó un cultivo láctico termófilo, liofilizado, de fermentación lenta, serie MY 800, marca Ezal ${ }^{\circledR}$, de Rodhia, conformado por Streptococcus thermophilus, Lactobacillus delbrueckii subsp. lactis y Lactobacillus delbruechii subsp. Bulgaricus.

Azúcar: Se utilizó azúcar refinada comercial. 


\section{Métodos de evaluación físico química}

Para determinar las características físicoquímicas necesarias durante toda la experimentación, se aplicaron los métodos siguientes:

$\square$ Sólidos totales por método gravimétrico según Método 990.20 AOAC, 1998.

$\square$ Cenizas por método gravimétrico mediante incineración según Método 942.05 AOAC, 1998.

च Proteína por el método Kjeldahl según Método 960.52 AOAC, 1998.

■ Fibra mediante determinación de Fibra cruda por el Método 962.09 AOAC, 1998.

$\square$ Grasa en leche por método Babcock según Método 942.05 AOAC, 1998.

$\square$ Acidez total, expresada como \% de ácido láctico, mediante valoración potenciométrica con potenciómetro Orión 420, por el Método 950.15 AOAC, 1998.

च PH se midió con un Potenciómetro Orión 420, de acuerdo con el Método 981.12 AOAC, 1998.

च Grados Brix por el método Refractométrico según el Método 983.17 AOAC, 1998.

च Contenido de Ácido láctico mediante Cromatografía Líquida de Alta Resolución (HPLC) según el método descrito por Marsili, 1981, haciendo uso de un Cromatógrafo Jasco, Bomba Jasco PU-980, Detector UV/9757, Paquete Borwin para manejo de datos y Columna de exclusión lónica $300 \times 7.8$ mm Aminex. $\mathrm{HPX}-87 \mathrm{H}$.

$\square$ Viscosidad utilizando un Viscosímetro Haake Rotovisco RV 20, con sistema MV, según Lewis, 1993.

■ Gravedad específica por picnometría por el Método 925.22 AOAC, 1998.

\section{Ensayos}

Para la fermentación se aplicó el procedimiento estudiado en trabajos previos (Quicazán y col., 2001b) agregando sacarosa en un nivel de 8\% antes de la pasteurización, utilizando el cultivo MY 800 e incubando a $42^{\circ} \mathrm{C}$. Se efectuaron tres repeticiones de cada ensayo y se tomaron muestras por duplicado, cada hora, durante 7 horas de fermentación. Las variables de respuesta seleccionadas para evaluar el proceso fermentativo fueron: $\mathrm{pH}$, acidez total, contenido de ácido láctico (determinado por HPLC) y viscosidad.

Se realizó un análisis de varianza con un nivel de significancia del 5\% (á=0,05) utilizando el programa SAS (Statistic Analysis System) considerando los dos tratamientos y las tres repeticiones realizadas. Para comparar los valores promedio de las variables y la significancia de las diferencias $(a=0,05)$, se calculó la diferencia media significativa aplicando la prueba de Tukey y el mismo programa estadístico.

La caracterización físico-química comprendió, además de las variables de respuesta seleccionadas, la determinación de las siguientes propiedades: contenido de sólidos, humedad, gravedad específica, grasa, fibra, proteína y cenizas.

\section{RESULTADOS Y DISCUSIÓN}

En la Tabla 1 se presentan los valores promedio obtenidos para las características físico-químicas de la bebida de soya y la leche de vaca estandarizada empleadas. La ausencia de lactosa y el bajo contenido de grasa de la bebida de soya explican su diferencia en el nivel de sólidos con la leche de vaca. Esto se refleja en las diferencias de gravedad específica y viscosidad.

En la Figura 1 se presentan los valores medios de la acidez total obtenidos durante la fermentación. El análisis estadístico permitió establecer que para todos los tiempos evaluados, las diferencias en esta propiedad son significativas a un nivel $a ́=0,05$. Aunque la bebida de soya sola es la que sufre menor acidificación, el valor encontrado para la acidez titulable es superior a la reportada en otros estudios (Pinthong y col., 1980a) en los que se expresa que la bebida de soya sola no alcanza valores superiores al $0.3 \%$ de acidez total si no se encuentra suplementada; esto puede ser 
debido al nivel de sólidos de la bebida de soya utilizada para la experimentación, tal como ha sido reportado por diferentes autores (Favaro y col., 2001).

Tabla 1. Características físico-químicas de la bebida de soya y la leche de vaca utilizadas

\begin{tabular}{||l|c|c||}
\hline \multicolumn{1}{|c|}{ Característica } & $\begin{array}{c}\text { Bebida de soya } \\
\text { Estandarizada }\end{array}$ & $\begin{array}{c}\text { Leche de vaca } \\
\text { Estandarizada }\end{array}$ \\
\hline Humedad (\%P/P) & 93,00 & 88,00 \\
\hline $\mathrm{pH}$ & 6,54 & 6,60 \\
\hline Acidez total (\%A. Láctico) & 0,06 & 0,14 \\
\hline Gravedad específica & 1,018 & 1,033 \\
\hline Sólidos total es (\%P/P) & 7,00 & 12,00 \\
\hline Grasa (\%P/P) & 0,75 & 3,00 \\
\hline Proteína(\%P/P) & 3,12 & 3,40 \\
\hline Fibra Cruda (\%P/P) & 0,30 & --- \\
\hline Grados Brix & 6,5 & --- \\
\hline Cenizas (\%P/P) & 0,42 & 0,84 \\
\hline Carbohidratos (\%P/P)* & $2,35^{*}$ & $4,61^{*}$ \\
\hline Ácido Láctico (\%P/P) & 0,043 & 0,11 \\
\hline Viscosidad (Pa.s) & 0,008 & 0,010 \\
\hline
\end{tabular}

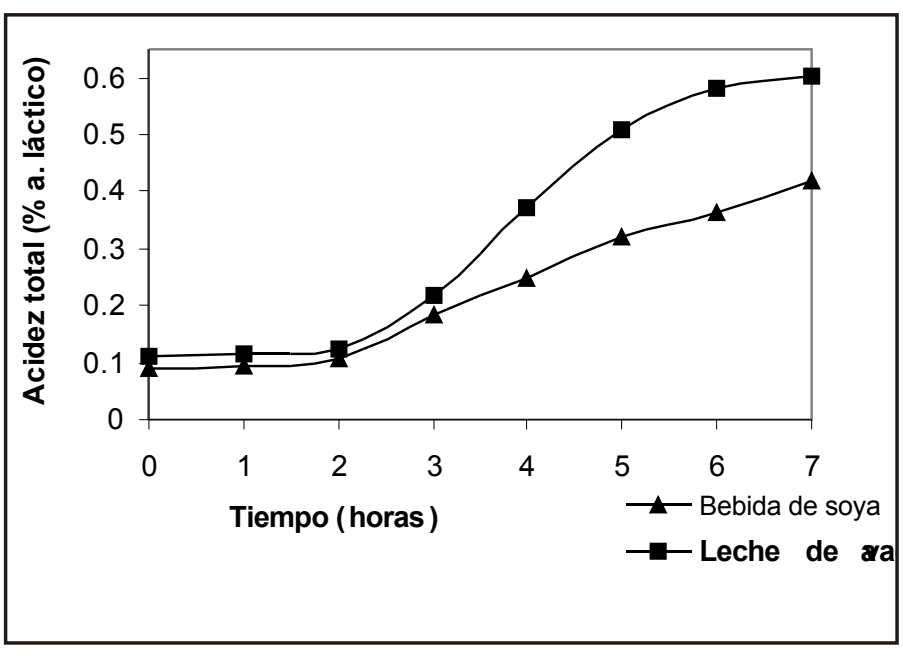

Figura 1. Comportamiento de la acidez total durante la fermentación de leche de soya y de leche de vaca

En la Figura 2 aparecen los valores promedio encontrados para el contenido de ácido láctico a los diferentes tiempos evaluados, cuyos valores son inferiores en la bebida de soya. Tanto para la bebida de soya como para la leche de vaca se encuentra que estas concentraciones son inferiores a los de acidez total. La evaluación estadística permitió concluir que los valores son significativamente diferentes durante todo el periodo evaluado. Además del ácido láctico, los análisis por HPLC demostraron que existen otros ácidos orgánicos que constituyen la acidez total, tales como el cítrico, el málico, el fumárico y el butírico. Aunque en el presente estudio no fueron cuantificados, es recomendable profundizar en este tema en trabajos futuros.

En la Figura 3 se muestra el comportamiento del $\mathrm{pH}$ durante la fermentación de bebida de soya y de leche de vaca. Se observa que, en los dos casos, la primera fase de latencia de la fermentación tiene una duración de dos horas, al cabo de las cuales se presenta la fase logarítmica, con un comportamiento muy similar entre sí; estadísticamente no se encontró diferencia entre los valores hasta a las 5 horas de fermentación.

Debido a la similitud de los valores del punto isoeléctrico para las proteínas de la bebida de soya y de la leche de vaca y tomando como criterio el pH de coagulación entre 4,5 y 4,6 , se encuentra que existe diferencia en el tiempo necesario para alcanzar este valor. La leche de vaca requiere 5 horas, mientras que la bebida de soya necesita 7 horas. Sin embargo se encuentra que para estos puntos, la proporción [Contenido de ácido láctico / Acidez total] es muy similar en las dos fermentaciones. Para la bebida de soya tiene un valor de 0,57 y para la leche de vaca 0,60. Como en esta experimentación se empleó un cultivo de fermentación lenta, esto indica que a pesar de que la bebida de soya no contiene lactosa, el cultivo efectivamente se adapta y acidifica en forma semejante a como sucede en la leche de vaca.

En la Figura 4 se presentan los valores medios de viscosidad aparente hallados durante la fermentación. El comportamiento de esta propiedad es semejante al encontrado para la acidez total y para el contenido de ácido láctico. Se encontró diferencia significativa entre los valores de viscosidad de la bebida de soya y los de leche de vaca, excepto a las 3 y a las 4 horas de fermentación. 


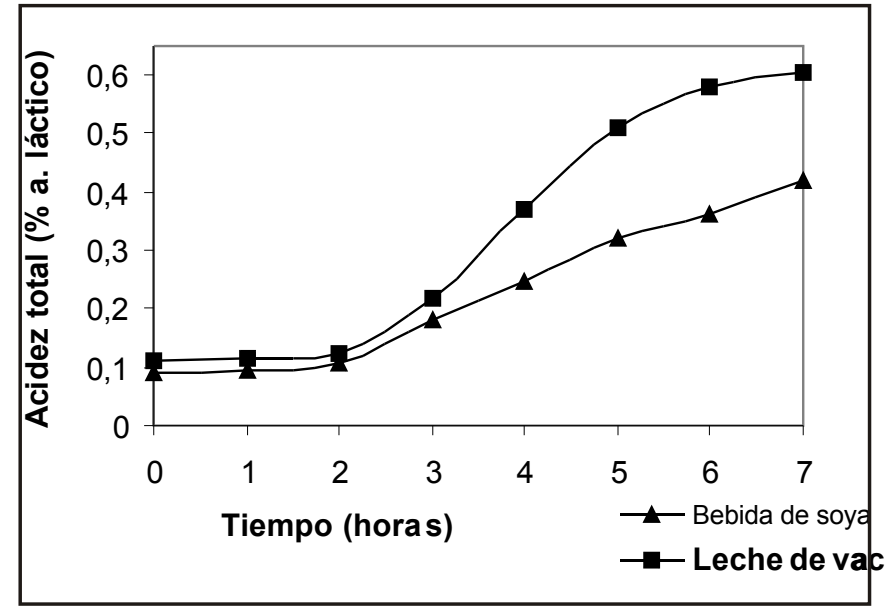

Figura 2. Comportamiento del contenido de ácido láctico durante la fermentación de leche de soya y de leche de vaca

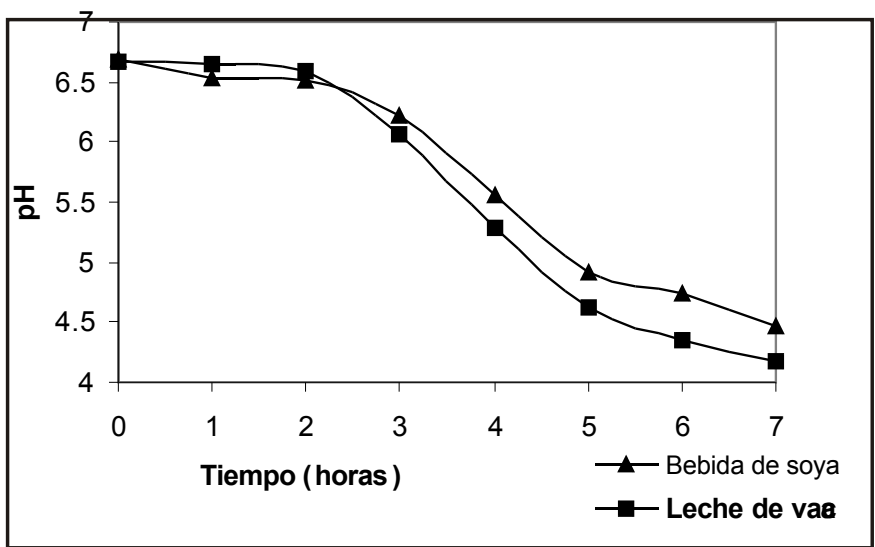

Figura 3. Comportamiento de $\mathrm{pH}$ durante la fermentación de bebida de soya y leche de vaca

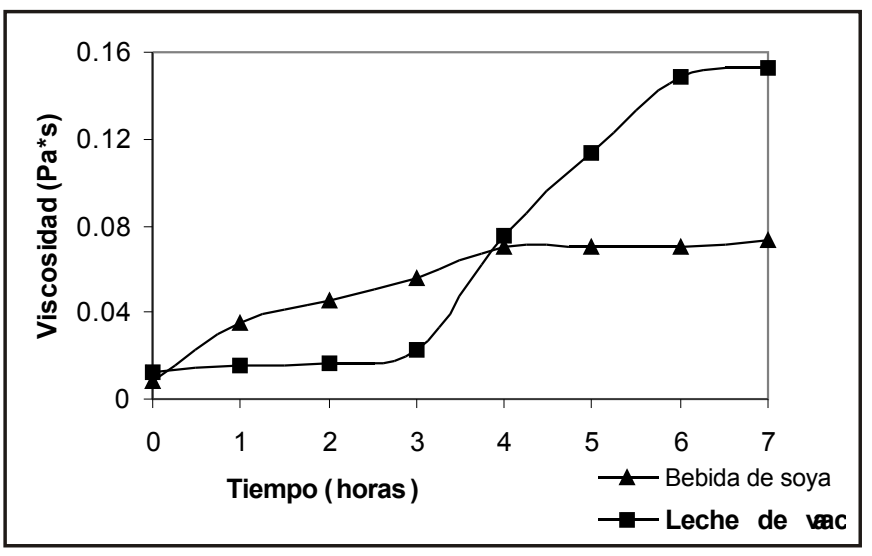

Figura 4. Comportamiento de la viscosidad durante la fermentación de bebida de soya y leche de vaca
Éstas se pueden explicar por las diferencias encontradas en la acidificación y por los inferiores contenidos de sólidos totales y de grasa en la bebida de soya.

\section{CONCLUSIONES Y RECOMENDACIONES}

La acidificación de la bebida de soya y la leche de vaca durante el proceso tiene un comportamiento directa y apreciablemente relacionado con el tiempo de fermentación. Los valores de acidez para la bebida de soya difieren significativamente de los de la leche de vaca, mientras que no sucede lo mismo para los valores de $\mathrm{pH}$.

El contenido de ácido láctico, determinado por HPLC, experimentó un incremento durante el proceso fermentativo. Tuvo valores apreciablemente inferiores a la acidez total del orden del $60 \%$. Se detectaron otros ácidos orgánicos además del láctico.

La viscosidad sufre un incremento que depende del tiempo de fermentación; los valores para la bebida de soya son significativamente inferiores a los de la leche de vaca.

Es recomendable continuar los estudios que profundicen en el conocimiento de este tipo de fermentación.

\section{BIBLIOGRAFÍA}

1. AMKEMMAM, G., and MORR, C. Improved acid flavor and volatile compound production in a high protein and fiber soymilk yogurt-like product. J. Food Science, 1996, 61(2): 331336.

2. AOAC IMTERMATIOMAL. Official Methods of Analysis. Version on CD-ROM. Gaithersburg, Maryland. USA. 16 ${ }^{\text {th }}$ Edition. $4^{\text {th }}$ Revision. 1998.

3. BESLER, Matthias. Composition of soybeans. Internet Symposium on Food Allergens, [online]. 1999, [2002], texto en inglés. 
Disponible en Internet: http://www.fooda ll ergens.de/sym posium vol1(2)/data/soy/soy-composition.htm

4. BUOMO, M., SETSER, C., ERICKSOM, L. and FUMG, D. Soymilk yoghurt: sensory evaluation and chemical measurement. J. Food Science, 1990, 55(2): 328-332.

5. CHAMG, C. Effect of total soymilk solids on acid production by selected Lactobacilli. J. of Food Science, 1990, 55(6): 322-325.

6. CHEMG, Y. and THOMPSOM, L. Sogurt, a yogurt-like soybean product. J. of Food Science, 1990, 55(4):532-536.

7. FAVARO, C., TERZI, S., TRUGO, L., DELLA MODESTA, R. and COURI, 5. Development and sensory evaluation of soy milk based yogurt. Archivos latinoamericanos de nutrición, 2001, 5(1): 100-104.

8. KROGER, M., ROGER, M., KURMAM, J. and RASIC, J. Fermented Milks: past, present and future. Food Tecnology, 1989, 43(1): 9299.

9. LEE, S-Y., MORR, C. and SEO, A Comparison of milk-based and soymilk-based yogurt. J. of Food Science, 1990, 55(2):532-536.

10.LEWIS, M. Propiedades Físicas de los Alimentos y de los Sistemas de Procesado. Zaragoza. España. 1993.

11.MARSILI, R., OSTAPEMKO, H., SIMMOMS, R. and GREEM, D. High performance liquid chromatographic determination of organic acids in dairy products. J. Food Science, 1981, 46: 52-57.

12. OBERMAM, H. Fermented milks, Microbiology of fermented foods. London. Elsiever Appl. Sci. Pub. 1985.
13.PIMTHOMG, R., MACRAE, R. and ROTHWELL, J. The development of soya-based yoghurt. I. Acid production by lactic acid bacteria. J. Food Technology, 1980a, 15:647-652.

14.PIMTHOMG, R., MACRAE, R. and ROTHWELL, J. The development of soya-based yoghurt. II. Sensory evaluation and analysis of volatiles. J. Food Technology, 1980b, 15: 653-659.

15.PIMTHOMG, R., MACRAE, R. and DICK, J. The development of soya-based yoghurt. III. Analysis of oligosaccharides. J. Food Technology, 1980c, 15: 661-667.

16.QUICAZÁM, M., SAMDOVAL, A. Y PADILLA, G. Evaluación de la fermentación de bebida de soya con un cultivo láctico. Revista Colombiana de Biotecnología, 2001, 3(2): 92-99.

17.ROBIMSOM,R. y TAMIME, A. Yogur: Ciencia y Tecnología. Zaragoza. Espana. Acribia. 1991.

18.U. S. B. UMITED SOYBEAM BOARD. Soy foods Guide: helpful tips and information for using soyfoods [online]. Soy Protein Partners, 2002, [2002], texto en inglés. Disponible en Internet:

http://soyfoods.com/SFG2002.pdf

19.VASCOMCELLOS, A.. Alimentos Funcionales: conceptos y beneficios para la salud [online]. Departamento de Ciencias de Alimentos y Mutrición. Universidad de Chapman, Orange, California, U:S:A:, 2001 [2001]. Disponible en Internet:

http://www.worldfoodscience.org/vol1_3/feat ure1-3a.html 